\title{
APORTES TEÓRICOS DA PSICOLOGIA HISTÓRICO-CULTURAL PARA A EDUCAÇÃO ESCOLAR DE ADOLESCENTES ${ }^{1}$
}

\author{
CONTRIBUTIONS OF PSYCHOLOGY HISTORICAL-CULTURAL FOR \\ EDUCATION OF TEENAGERS
}

\author{
ANJOS, Ricardo Eleutério dos \\ ricardo.eleuterio@hotmail.com \\ UNESP - Araraquara
}

\begin{abstract}
RESUMO O presente artigo apresenta a concepção de adolescência a partir dos pressupostos da psicologia histórico-cultural, bem como sua contribuição à educação escolar nesta fase do desenvolvimento humano. Considerando-se que, para Vigotski, a adolescência é um momento privilegiado tanto pelo desenvolvimento do pensamento por conceitos, como pela formação da concepção de mundo e desenvolvimento da autoconsciência, a hipótese deste trabalho é a de que a educação escolar pode contribuir decisivamente, por meio do ensino do conhecimento sistematizado, para o desenvolvimento psicológico dos adolescentes, no sentido da superação dos limites dos conceitos cotidianos. Para tanto, este artigo apresentará a premente necessidade da superação das concepções naturalizantes evidenciadas pelas correntes liberais em psicologia. Essas concepções de adolescência contrastam com o ponto fulcral no qual Vigotski e colaboradores concentraram suas pesquisas, a saber, a formação dos conceitos como um salto qualitativo no desenvolvimento psicológico nesta fase por eles chamada "idade de transição".
\end{abstract}

PALAVRAS-CHAVE: Adolescência. Pensamento conceitual. Psicologia históricocultural. Educação escolar.

ABSTRACT This article aims to present the conception of adolescence from the assumptions of cultural-historical psychology as well as their contribution to school education at this stage of human development. Considering that, for Vygotsky, adolescence is a privileged moment in both the development of thinking by concepts such as the formation of the world conception and development of selfconsciousness, the working hypothesis is that school education can decisively contribute, by through the teaching of systematic knowledge for the psychological development of adolescents in order to overcome the limits of everyday concepts. Therefore, this paper will present the urgent need to overcome the naturalizing

\footnotetext{
${ }^{1}$ Este artigo é parte integrante da pesquisa de mestrado do autor e contou com o apoio financeiro da CAPES.
} 
conceptions evidenced by the liberal trends in psychology. These conceptions of adolescence contrast with the focal point in which Vygotsky and colleagues focused their research, namely the formation of concepts as a quantum leap in psychological development at this stage they call "age of transition."

KEYWORDS: Adolescence. Conceptual thinking. Cultural-historical psychology. School education.

\section{INTRODUÇÃO}

Os conhecimentos hegemônicos em psicologia do adolescente, bem como sua contribuição à educação escolar dessa fase do desenvolvimento humano, estão embasados em concepções biológicas, naturalizantes, abstratas e patologizantes. Estes pressupostos sobre a adolescência contrastam com o ponto fulcral no qual Vigotski $^{2}$ e colaboradores concentraram suas pesquisas, a saber, a formação dos conceitos como um salto qualitativo no desenvolvimento psicológico nesta fase, por eles chamada "idade de transição".

No campo psicológico, Stanley Hall (1844-1924) foi um dos precursores na pesquisa sobre adolescência. Este pesquisador denomina este período que, para ele compreende dos 12 aos 24 anos, de "segundo nascimento", por se tratar do período em que se manifestam os traços mais desenvolvidos essencialmente humanos. Hall defendia a ideia de que a ontogênese repete a filogênese e, no caso da adolescência, tal fase representaria o período em que a espécie humana encontrava-se em transição e turbulência. Isto explicaria as tensões e sofrimentos psicológicos que caracterizam os adolescentes. Segundo Griffa e Moreno (2010) e também Palacios e Oliva (2004), Hall teria afirmado, em sua obra Adolescence, de 1904, que a adolescência corresponde ao momento da evolução da espécie humana que representa a passagem da selvageria ao mundo civilizado.

Este trabalho não tem como objetivo detalhar as concepções naturalizantes sobre a adolescência, pois esta temática foi analisada por Bock (2004), Mascagna (2009), Ozella (2003), entre outros. No entanto, indica-se um claro exemplo que legitima a asserção acima, ou seja, a de que a psicologia naturalizou e patologizou a

\footnotetext{
${ }^{2}$ O nome Vigotski é encontrado na literatura de várias formas, tais como Vygotsky, Vygotski, Vigotskii. A grafia "Vigotski" será padronizada neste artigo, porém, quando se tratar de referência a uma obra específica, será utilizada a forma que fora registrada no original.
} 
adolescência. Trata-se da teoria da Síndrome da Adolescência Normal de Knobel, que defende a naturalização do desenvolvimento humano ao considerar as características encontradas em adolescentes como um fator normal e inerente a esta fase de desenvolvimento.

Knobel (1992) afirma que os comportamentos dos adolescentes são semipatológicos, entre eles estão: a tendência grupal; a necessidade de intelectualizar e fantasiar; crises religiosas; desestruturação temporal; a evolução sexual desde o autoerotismo até a heterossexualidade; atitude social reivindicatória; contradições sucessivas em todas as manifestações; separação progressiva dos pais; constante flutuação do humor e do estado de ânimo. Para este autor, a não manifestação destes comportamentos semipatológicos é que sinalizaria um fenômeno anormal no adolescente.

A psicologia tradicional, desta forma, considera a adolescência como uma fase natural do desenvolvimento, fase esta, repleta de problemas e conflitos inerentes ao ser humano. Com isso, desconsiderou todo o processo histórico e social que constitui a adolescência. O aspecto social é considerado apenas um meio que impede ou auxilia o desenvolvimento de algo que é intrínseco à natureza humana. Infelizmente não perdeu sua atualidade a constatação feita por Vigotski, nos anos de 1930, de que a psicologia considera a adolescência como uma fase caracterizada por tormentos, problemas emocionais e conturbações vinculadas à sexualidade. Entre todas as mudanças que ocorre na infância à adolescência, Vigotski (1996) identificou que as teorias psicológicas de sua época destacavam apenas o ponto mais superficial e visível, qual seja: a mudança do estado emocional.

Esta ideia é reforçada e legitimada pela psicanálise e, consequentemente, esta concepção ficou impregnada "na definição dos adolescentes por livros, teorias, a mídia, profissionais das áreas das Ciências Humanas, e incorporada pela população e pelos próprios adolescentes" (OZELLA, 2003, p. 19).

Observa-se em tempos hodiernos, como também no passado, que as mudanças ocorridas na adolescência são explicadas de forma metafísica e subjetivista. Freud, por exemplo, dizia que na adolescência o indivíduo experimentava um retorno ao Complexo de Édipo e que deveria superá-lo por meio 
do afastamento de seus pais, a fim de escolher um objeto sexual socialmente aceito (PALACIOS; OLIVA, 2004).

Por outro lado, observa-se também que a adolescência é explicada apenas por uma concepção biologizante. Esta unilateralidade biológica, que considera a adolescência uma fase de perturbações vinculadas à sexualidade, é influenciada pelos estudos das mudanças corporais ocorrentes na puberdade. Porém, a puberdade, de acordo com Palacios e Oliva (2004), é apenas um dos "lados da moeda" que explica a adolescência, pois se trata do conjunto de mudanças físicas que transformam o corpo infantil em um corpo adulto capacitado para a reprodução biológica da espécie.

Nesta fase, ou seja, entre os 10 aos 17 anos, ocorrem várias mudanças corporais como hormônios-estímulos (hormônios gonadotróficos da hipófise anterior ou hormônios sexuais como a testosterona, estrógenos e progesterona oriundos das gônadas sexuais), produzindo óvulos ou espermatozoides, bem como o aumento do pênis e dos testículos no rapaz e o aumento do útero e da vagina na mulher. Segundo Griffa e Moreno (2010), estes são os caracteres sexuais primários. Além dos caracteres sexuais primários, ocorre também o desenvolvimento dos caracteres sexuais secundários que se constituem no aumento das mamas, por conta do desenvolvimento glandular e distribuição de gorduras, mudanças da voz, crescimento de pelos no púbis e nas axilas, mudanças estas que ocorrem de maneira distinta de acordo com o sexo, incluindo, também, o aparecimento da barba no homem.

Elkonin (1960) chama a atenção sobre um ponto importante, qual seja: que a psicologia tradicional tenta explicar todas as características dos adolescentes, incluindo as psicológicas, somente por motivos biológicos, ligando as particularidades de sua personalidade com o fato da maturação sexual. Segundo o autor, a maturação sexual, como todos os outros aspectos do desenvolvimento físico, embora incluam particularidades fundamentais no desenvolvimento psíquico, não têm uma influência determinante na formação da personalidade do adolescente.

É importante que se diga que as mudanças biológicas ocorridas na adolescência, ou em qualquer outra fase do desenvolvimento humano, não podem ser negadas ou negligenciadas, pois as relações entre o biológico e o social no ser 
humano são de incorporação daquele por este e não de eliminação ou mesmo separação entre ambos. Discordar das concepções naturalizantes não significa negar as influências da materialidade orgânica do corpo humano na vida de uma pessoa. Daí a importância do materialismo histórico-dialético para o que se propõe: uma correta compreensão desses fenômenos.

Portanto, o nível alcançado pelas possibilidades físicas, volitivas e morais na adolescência cria, segundo Elkonin (1960), as premissas necessárias para que mude fundamentalmente a situação do adolescente na sociedade. Para este autor,

É indubitável que, por exemplo, a aparição dos caracteres sexuais secundários, como a mudança do timbre da voz dos meninos, a aparição do pelo no púbis, a formação das glândulas mamárias nas meninas, faz com que os próprios adolescentes entre si e os adultos não os considerem mais como crianças. Este é um dos momentos fundamentais que determinam a nova situação do adolescente entre os adultos que os rodeiam e tem uma influência indubitável na formação de sua personalidade. Não menos significação tem a aparição do desejo sexual. (ELKONIN, 1960, p. 539).

Destarte, as multideterminações que estão ligadas à vida do adolescente determinam sua vida psíquica. Fica evidente, por meio do excerto acima, que a formação psíquica do adolescente não é oriunda diretamente do processo de maturação sexual, mas sim, de várias outras influências como a situação social que o rodeia, a complexidade da atividade escolar, a ampliação das relações sociais, a crescente independência, bem como as novas exigências feitas a ele pelos adultos.

Ozella (2003), após sua pesquisa sobre qual o significado que os psicólogos dão à adolescência, verificou que, na maioria dos profissionais entrevistados, houve o predomínio da visão liberal de ser humano, que teria como características principais uma concepção que analisa a vida a partir de características originariamente individuais, bem como uma naturalização e eternização do tipo burguês como representando a realização da essência humana.

Bock (2004) e também Mascagna (2009) evidenciaram esta mesma concepção de adolescência ao analisarem alguns textos em livros e revistas publicados para professores e pais de adolescentes. Mascagna (2009, p. 26), ao analisar artigos sobre o tema adolescência na base de dados científicos Scielo, chama a atenção para um interessante ponto: 
Qualquer estudante e/ou pesquisador que fizer uma pesquisa na Scielo a fim de compreender a adolescência se apropriará das teorias idealistas sobre o tema em questão ou as reforçará. Também pudemos observar o quanto as teorias biologicistas estão no meio acadêmico e como essa visão naturalizante do homem é disseminada cientificamente como verdade. A visão biologicista de adolescência universaliza 0 desenvolvimento psicológico em fases naturais e inerentes ao próprio homem.

Outra abordagem que exerce relevante papel na atualidade e, principalmente, no campo da educação, é a Epistemologia Genética de Jean Piaget. Mostrando que um dos postulados essenciais da teoria de Piaget é o de que a aquisição de conhecimentos socialmente existentes não produz desenvolvimento cognitivo, Vigotsky (1995, p. 123) se contrapõe a teoria asseverando que:

\footnotetext{
O ensino é uma das principais fontes de conceitos da criança em idade escolar, e é também uma poderosa força que direciona o seu desenvolvimento. Determina o destino de sua evolução mental completa. Deste modo, os resultados do estudo psicológico dos conceitos infantis podem aplicar-se aos problemas do aprendizado de uma forma muito diferente daquela imaginada por Piaget.
}

Isto quer dizer que o ensino será a força propulsora do desenvolvimento psíquico e da formação dos conceitos científicos no adolescente escolar. Conforme Vigotski (2006, p. 114), “o único bom ensino é o que se adianta ao desenvolvimento".

O ponto que justifica o tema deste artigo está contido nas considerações acima e fica evidente a necessidade de apresentar uma concepção de adolescência numa abordagem histórico-cultural. Ou seja, uma concepção de adolescência que supere a visão idealista, naturalista, biologizante e patologizante.

\section{A ADOLESCÊNCIA NA CONCEPÇÃO DA PSICOLOGIA HISTÓRICO-}

\section{CULTURAL}

No âmbito do presente estudo, tomar-se-á como foco específico a importância da educação escolar na promoção do desenvolvimento do adolescente. Entretanto, não se ignora a existência de outra realidade, a do adolescente que, vivendo no campo ou na cidade, não esteja inserido na escola. 
A psicologia histórico-cultural considera que a adolescência, como fase do desenvolvimento psicológico, tem sua origem na história das transformações pelas quais passaram as sociedades, ou seja, as transformações dos modos de produção. Um primeiro ponto a ser considerado é o de que a adolescência surgiu em consequência de um determinado grau, historicamente alcançado, de complexidade da vida social.

Em determinadas sociedades, por exemplo, o indivíduo ao chegar à puberdade, passava por certos rituais de iniciação que o legitimavam como adulto. Ariès (1978) comenta que, até o século XVIII, o indivíduo passava da condição de criança para adulto sem necessariamente viver a condição da adolescência. Este indivíduo participava da vida adulta, crescia misturado com os adultos e aprendia os comportamentos sociais por meio do contato direto com eles. Segundo o autor, foi somente a partir do século XIX que a adolescência passou a ser considerada uma fase distinta da infância e da vida adulta.

Neste mesmo século, as crianças se incorporavam ao mundo do trabalho em algum momento entre os sete anos e o começo da puberdade. Poucas crianças estudavam. Somente os filhos das classes altas e, as que estudavam, tinham em média de 10 ou 12 anos. Geralmente, não estavam agrupadas em níveis de idades diferenciados, nem permaneciam muito tempo no sistema educacional. Foi no final do século XIX, devido à revolução industrial, que houve uma notável mudança neste contexto acima citado, pois, com a industrialização, a formação e os estudos passaram a ser importantes. Porém, isso só ocorrera com os filhos das classes médias e altas. Os filhos de operários, mesmo em idades muito precoces, continuaram por longo tempo no mundo do trabalho (ARIÈS, 1978; ISAMBERTJAMATI, 1966).

De acordo com Bock (2004), devido à revolução industrial, ocorreram grandes mudanças no modo de viver dos indivíduos. O avanço tecnológico trouxe em seu bojo a exigência de capacitação profissional para que o indivíduo pudesse adentrar no mundo do trabalho. Com isso, outra exigência ocorreu, a saber, um considerável prolongamento do tempo de formação, obviamente, reunindo os adolescentes por mais tempo na escola. Em razão disso, afirma a autora, os adolescentes teriam começado a se distanciar dos pais e, consequentemente, formado um novo grupo e 
construído uma nova fase de desenvolvimento. Para Bock (2004, p. 41), "a adolescência refere-se, assim, a esse período de latência social constituída a partir da sociedade capitalista, gerada por questões de ingresso no mercado de trabalho e extensão do período escolar, da necessidade do preparo técnico".

Além da discussão que Bock realiza, é importante destacar que o citado distanciamento dos pais não fora causado apenas pela inserção do adolescente na escola, nem o prolongamento desta fase de transição fora reflexo do prolongamento do tempo de escolaridade. Isso, reiterando, aconteceu apenas com as camadas privilegiadas da sociedade, ou seja, com a burguesia. Isambert-Jamati (1966) afirma que, durante muito tempo, a maior parte da população foi separada de seus pais, devido ao contrato anual de trabalho dos jovens rurais, ou devido à aprendizagem junto de um artífice distante. Esta autora assevera que tais rupturas eram praticamente definitivas e tais compromissos, bem como a entrada ao exército, convento ou seminário, frequentemente aconteciam a partir dos 12 ou 13 anos de vida. Enquanto a industrialização do século XIX obrigou as classes inferiores a uma infância muito curta, causando a dissociação das famílias de classe operária por serem compelidas a enviarem seus filhos para o trabalho a partir dos oito anos de idade, a burguesia, por sua vez, ofereceu longos estudos para seus filhos, no objetivo de prepará-los para os negócios econômicos.

Não é objetivo deste artigo apresentar um levantamento das pesquisas nos campos da história e da sociologia sobre a adolescência. Essas poucas e rápidas menções a discussões sobre as circunstâncias histórico-sociais que levaram ao surgimento da adolescência têm tão somente a intenção de registrar a consciência da complexidade dessa temática. Um pressuposto central deste estudo é o de que a adolescência é um fenômeno produzido pela história das sociedades divididas em classes sociais.

A adolescência, para a psicologia histórico-cultural, portanto, não pode ser reduzida apenas a um processo de mudanças biológicas, naturais, caracterizadas por consequentes síndromes devido aos "hormônios que estão à flor da pele". Vygotski (1996) afirma que os cientistas biologistas equivocam-se, com grande frequência, ao considerar o adolescente um ser apenas biológico, natural. 
O adolescente é, sobretudo, um ser histórico e social (VYGOTSKI, 1996). Isso não significa, entretanto, que Vigotski e outros psicólogos dessa corrente desconsiderassem ou secundarizassem a importância da materialidade biológica no desenvolvimento psicológico humano. O caráter histórico e social do psiquismo humano estrutura-se sobre a base dos processos neurofisiológicos e qualquer psicologia que desconsidere esse fato estará fora do campo científico. Portanto, a evolução biológica não está paralisada, nem a espécie humana cristalizou-se a partir de sua vida em sociedade. O que ocorreu foi que as leis biológicas e as características determinantes do desenvolvimento humano pautadas na hereditariedade não são mais as forças motrizes do desenvolvimento humano, pois cederam lugar às leis sócio-históricas.

Vygotski (1996) afirma que os interesses são a chave para entender o desenvolvimento psicológico do adolescente, pois se constituem, em maior escala, o conteúdo do desenvolvimento social e histórico do que simplesmente o aspecto biológico. Tal asserção legitima o caráter cultural e histórico na formação do indivíduo. Os velhos interesses da infância vão desaparecendo e surgem novos interesses. Para Vigotski, o processo de extinção dos velhos interesses e o desenvolvimento dos novos é, particularmente, um processo longo, sensível e doloroso. Para este autor, existem períodos de crise no desenvolvimento humano e a perda dos interesses que antes orientavam a atividade do indivíduo provoca a necessidade de uma viragem. Não obstante, as crises que o adolescente enfrenta marcam o surgimento de uma nova forma de pensar.

Vygotski (1996) propõe uma superação da ideia hegemônica sobre o conteúdo e a forma do pensamento do adolescente. De acordo com o autor, a psicologia tradicional defendia que não havia nada novo no pensamento do adolescente em comparação ao pensamento de uma criança de tenra idade. A psicologia tradicional, portanto, não explicou as causas e as características da crise da adolescência, pois postulava que o pensamento do adolescente se fortalecia, crescia e se incrementava, porém, não aparecia nenhuma operação intelectual nova.

Entre todas as mudanças que ocorrem na infância à adolescência, estas correntes psicológicas citadas por Vigotski destacavam apenas o ponto mais superficial e visível, qual seja: a mudança do estado emocional. Para o autor, isto 
significa olhar o fenômeno de cabeça para baixo. Ele destaca que, ao contrário do que afirmavam essas teorias, a criança de tenra idade é um ser eminentemente emocional, ao passo que o adolescente, sobretudo, é um ser pensante.

Vygotski (1996, p. 49), então, faz a seguinte afirmação em relação a essa inversão realizada pelas teorias psicológicas por ele criticadas:

O desenvolvimento sucessivo de tal ponto de vista conduz à banal concepção que deseja reduzir toda a maturação psíquica do adolescente a uma elevada emotividade, a impulsos, imaginações e demais produções românticas da vida emocional. $O$ fato de que o período da maturação sexual seja um período de potente auge no desenvolvimento intelectual, que pela primeira vez o pensamento ocupe, neste período, o primeiro plano, não só passa despercebido com semelhante formulação, mas parece até misterioso e inexplicável.

Vygotski (1996) identificou que as teorias psicológicas predominantes nas primeiras décadas do século XX negavam o surgimento de novas formas de pensamento na adolescência. Estas teorias defendiam que todas as mudanças no pensamento do adolescente resumiam-se a um avanço ulterior pelas vias já traçadas no pensamento da criança, ou seja, tanto no adolescente quanto na criança de tenra idade, a forma de pensar era a mesma, havendo mudanças apenas no conteúdo do pensamento. Estabelecia-se, dessa maneira, uma ruptura entre forma e conteúdo de pensamento. Diante desta visão dualista e metafísica, a psicologia tradicional defendia que a diferença entre a criança e o adolescente resumia-se ao fato de que as mesmas formas do pensamento têm conteúdos diferentes.

Vigotski considera tosca e primitiva a visão contida nessas teorias, para as quais os novos conteúdos da vida do adolescente, por mais importantes e revolucionários que sejam, em nada alterariam as formas de pensar, que seriam como um recipiente no qual novos conteúdos seriam introduzidos sem provocar modificação do próprio recipiente. Contrapondo-se a essa visão, Vigotski afirma que tanto os conteúdos como as formas de pensamento desenvolvem-se histórica e dialeticamente. Em outras palavras, tanto na história social da humanidade como no desenvolvimento psicológico individual surgem funções psicológicas novas e superiores, indispensáveis à ampliação dos horizontes culturais coletivos e individuais. Nesse momento de seu texto, Vygotski estabelece uma forte relação entre a unidade conteúdo e forma, das relações entre pensamento e linguagem e 
das relações entre as funções psíquicas elementares e superiores (VYGOTSKI, 1996).

Esta nova forma de pensamento que caracteriza a adolescência é a formação de conceitos. Para Vigotski, o pensamento por conceitos é o passo a uma forma nova e superior de atividade intelectual, um modo novo de conduta e a chave de todo o problema do desenvolvimento do pensamento. A formação de conceitos, na adolescência, se encontra no centro do desenvolvimento do pensamento e "trata-se de um processo que representa na realidade as autênticas mudanças revolucionárias tanto no conteúdo como nas formas de pensamento." (VYGOTSKI, 1996, p. 58).

De acordo com os resultados de suas pesquisas, Vigotski $(2010,1996)$ evidencia que o desenvolvimento do pensamento por conceitos atravessa vários estágios, quais sejam: o estágio do sincretismo; o estágio do pensamento por complexos; e os conceitos propriamente ditos. Na primeira infância até a idade préescolar, a criança opera cognitivamente com agrupamentos sincréticos, pensamento por complexos e com pseudoconceitos. Segundo o autor, a forma superior de pensamento conceitual se tornará possível apenas na adolescência. E acrescenta que somente pelo pensamento por conceitos é que a ciência, a arte e demais produções sociais poderão ser apropriadas de forma aprofundada.

Neste contexto, Vigotski (2010) analisou especialmente a formação de dois tipos de conceitos e das relações entre eles, a saber, os conceitos cotidianos e os conceitos científicos. Os conceitos cotidianos são formados na educação não escolar que ocorre na prática cotidiana, ao passo que os conceitos científicos desenvolvem-se a partir do ensino escolar.

Duarte (2000, p. 86) explica que, para Vigotski, "os conceitos científicos, ao serem ensinados à criança através da educação escolar, superam por incorporação os conceitos cotidianos, ao mesmo tempo em que a aprendizagem daqueles ocorre sobre a base da formação destes". Ao operar com os conceitos cotidianos ou espontâneos, a criança não tem consciência destes conceitos, pois sua atenção está sempre centrada no objeto a que o conceito se refere e não no próprio ato de pensamento. Ao operar com os conceitos científicos, a criança começa 
simultaneamente a operar sobre o objeto ao qual o conceito se refere e sobre o próprio conceito, isto é, o próprio ato de pensar sobre o objeto.

Vigotski (2010, p. 293-294) ressalta que "Marx definiu com profundidade a essência de todo o conceito científico: 'Se a forma da manifestação e a essência das coisas coincidissem imediatamente, toda ciência seria desnecessária”". No conceito científico, portanto, o adolescente pode refletir sobre o que não está ao alcance dos conceitos cotidianos e pode conhecer a essência do objeto ou fenômeno dado. $E$ a educação escolar tem um papel fundamental neste processo, ou seja, na mediação entre os conceitos espontâneos e os conceitos científicos.

Destarte, o trabalho educativo possibilita ao indivíduo ir além dos limites dos conceitos cotidianos. Tais conceitos, como mencionado, são superados por incorporação pelos conceitos científicos e, como afirmou Vygotski (1996, p. 200), o pensamento conceitual produz o desenvolvimento da personalidade e da concepção de mundo do adolescente.

\section{A EDUCAÇÃO ESCOLAR DE ADOLESCENTES}

A ciência, a arte, a filosofia e demais produções do gênero humano podem ser apropriadas de forma aprofundada somente por meio do pensamento por conceitos, ou seja, somente a partir da adolescência (VYGOTSKI, 1996). Esse raciocínio pode ser dividido em dois pontos: o primeiro seria 0 de que 0 conhecimento dos processos essenciais da realidade só é possível quando o indivíduo torna-se capaz de pensar por conceitos; o segundo raciocínio refere-se a quando o indivíduo, na ontogênese, desenvolve o pensamento por conceitos e, para Vigotski, é a partir da adolescência.

A adolescência é um período propício para se operar o processo de apropriação das mais diversas esferas da vida cultural. Porém, como afirma Vigotski, este processo só acontece no momento em que o adolescente assimila corretamente esse conteúdo. Quando Vigotski fala sobre assimilar um conteúdo, isso implica uma transmissão precedente deste conteúdo mediada por ações de ensino. Se, para Vigotski, os conceitos científicos são produtos da educação organizada, isto reforça ainda mais a importância da escola como mediadora entre o 
cotidiano e o não cotidiano na formação do indivíduo, como também postulou Duarte (1996).

É na primeira infância que se encontra a raiz para o desenvolvimento dos processos que possibilitam a formação dos conceitos, porém, as funções psicológicas, necessárias para a formação do pensamento conceitual, desenvolvemse de maneira plena somente na fase de transição, ou seja, na adolescência. Para Elkonin (1960), as exigências do meio social impostas ao adolescente, bem como as novas responsabilidades a ele confiadas, são fatores determinantes no desenvolvimento psíquico nesta idade. O nível alcançado pelas possibilidades físicas, intelectuais, volitivas e morais da criança cria as premissas necessárias para que mude fundamentalmente a situação do adolescente na sociedade.

Este autor identificou que, na escola Soviética, as disciplinas transmitidas aos adolescentes diferenciavam-se muito daquelas transmitidas aos escolares de menor idade. Devido ao maior grau de complexidade nas disciplinas escolares, as leis gerais da realidade começaram a ocupar um lugar importante, manifestadas no sistema de conceitos de cada ciência. Ou seja, as disciplinas escolares transmitidas aos adolescentes, segundo Elkonin (1960), exigiam que estes aprendessem muitos conceitos abstratos, que se apoiam no conhecimento dos objetos concretos, mas, ao mesmo tempo, saem desses limites. Segundo o autor,

\footnotetext{
Decisivamente, a abstração do concreto é distinta nas diferentes disciplinas: em umas é maior (na geometria, na álgebra, na gramática), em outras, menor (na história, na geografia). Todavia, seja o que forma o caráter da conexão que há entre os conceitos abstratos e os objetos concretos, o mais típico e novo que contém os conhecimentos que adquire o adolescente é a abstração do concreto. (EKONIN, 1960, p. 536-537).
}

Além disso, o desenvolvimento da linguagem tem um enorme significado para o desenvolvimento psíquico dos adolescentes. A assimilação das formas mais complexas de orações com a utilização de diferentes conjunções (embora, porém, que, porque, entretanto, etc.), particípios e gerúndios, etc. criam "uma base para designar variadas dependências complexas entre os objetos e fenômenos (relações causais, funcionais, condicionadas, etc.) que são objeto de estudo das matemáticas, da história, da geografia, da física e de outras matérias". (ELKONIN, 1960, p. 541 542). 
A formação de conceitos é uma das causas fundamentais de todas as mudanças que se produzem no pensamento do adolescente. O ser humano não conseguiria dominar os processos mais complexos e profundos da realidade sem o pensamento conceitual que se dá a partir das relações recíprocas entre pensamento e linguagem. Segundo Vygotski (1996, p. 71) "o pensamento por conceitos revela os profundos nexos da realidade, revela as leis que a regem [...]". O desenvolvimento do pensamento conceitual permite que $\mathrm{o}$ adolescente tenha $\mathrm{o}$ profundo conhecimento da realidade interna, ou seja, o mundo de suas próprias vivências.

Vygotski (1996, p. 73) afirma que "graças ao pensamento por conceitos chegamos a compreender a realidade, a dos demais e a nossa própria". Para o autor, o pensamento por conceitos é a nova forma de pensamento que difere o adolescente das crianças menores e essa é a "revolução que se produz no pensamento e na consciência do adolescente".

Porém, essa revolução não acontece naturalmente, espontaneamente, não é fruto de maturação biológica senão da apropriação de objetivações genéricas mais elaboradas, como a ciência, a arte e a filosofia. Em suas pesquisas, Elkonin (1960) afirma que umas das particularidades dos interesses do adolescente é seu caráter ativo, conduzindo, algumas vezes, ao desprezo dos conhecimentos científicos e técnicos por considerá-los sem significado prático. A escola, deste modo, deve produzir necessidades de conhecimento sistematizado nos alunos. Para que isso seja feito, no trabalho educativo, deve-se deixar claro que o conhecimento, no início da atividade humana, foi produzido a partir de necessidades práticas e cotidianas, porém se libertou de uma dependência imediata deste cotidiano por meio da ciência, da arte e da filosofia.

Por outro lado, Vygotski (1996, p. 67) comenta sobre o caráter contraditório do adolescente e, embora Elkonin possa estar certo em relação a esse pragmatismo do adolescente, Vigotski menciona que o adolescente também tem inclinação para ideias metafísicas e românticas.

Vygotski identificou que alguns autores da época, como Blonski, constataram que, por um lado, o adolescente manifestaria interesse pela matemática, pela física e pela filosofia, numa busca de compreensão racional e lógica do mundo, mas, por 
outro, revelaria um "romantismo das ideias", no sentido de idealismo, de dificuldade de lidar com a realidade.

Alguns desses autores tentaram explicar essa contradição por causas biológicas, mas Vigotski discorda deles e explica pela análise do processo de desenvolvimento do adolescente. Ou seja, pela contradição entre a nova forma de pensamento que está em desenvolvimento (o pensamento por conceitos) e o fato de que esse novo estágio é ainda muito instável e o adolescente não consegue, a princípio, lidar com tudo o que deseja. O adolescente está aprendendo a pensar por conceitos e seria demais exigir que ele já pensasse dialeticamente e, por isso, acaba demonstrando uma unilateralidade de pensamento: "ou é isso ou é aquilo".

Vygotski (1996, p. 68) mostra que existe uma contradição entre o que se apresenta ao adolescente nesse descortinar-se de um mundo mais amplo para ele e as possibilidades de seu pensamento, que está dando um salto gigantesco no sentido do pensamento por conceitos, mas ainda não para o pensamento dialético. Para o autor, existe uma "insuficiência de dialética no pensamento do adolescente".

Ressalta-se, neste momento, o desafio da educação escolar de adolescentes, pois o pensamento dialético não está amplamente difundido na sociedade e nos campos das ciências, da filosofia e das artes. E, por consequência disso, o adolescente raramente se depara com esses modelos.

Destarte, ao contrário das pedagogias contemporâneas que defendem o cotidiano e a espontaneidade como pressupostos indispensáveis à educação escolar, considera-se que o trabalho educativo deve diferenciar-se do cotidiano. A escola deve "afastar" o aluno da vida cotidiana e formar um espaço diferenciado para o estudo do conhecimento sistematizado, possibilitando a ampliação das necessidades do indivíduo para além daquelas limitadas à esfera da vida cotidiana e daquelas pautadas apenas nas competências de alunos e professores, a fim de suprir as necessidades do capital. Este "afastamento" não significa, de maneira alguma, fuga à realidade. Trata-se da construção das mediações entre a prática cotidiana e a teoria, de maneira que aquela não seja guiada pura e simplesmente pelo pragmatismo imediatista e esta não se transforme em pura especulação metafísica e até mesmo transcendente. 
O trabalho educativo, portanto, realiza uma mediação, na formação do indivíduo, entre os conceitos cotidianos e os conceitos científicos, não cotidianos. Diante de tal importância que tem a educação escolar neste processo, fica evidente a urgência da superação das ideias propagadas pelas pedagogias contemporâneas baseadas no lema "aprender a aprender". Segundo Duarte (2010, p. 37), uma ideia muito difundida pelas pedagogias contemporâneas é a de que "o cotidiano do aluno deve ser a referência central para as atividades escolares"; na perspectiva dessas pedagogias "são considerados conteúdos significativos e relevantes para o aluno aqueles que tenham alguma utilidade prática em seu cotidiano".

Duarte (2001) denomina de pedagogias do "aprender a aprender" as que, neste contexto da relação entre educação escolar e conhecimento, apresentam uma visão negativa sobre a transmissão do conhecimento científico por parte da escola, limitando este conhecimento e atrelando-o ao cotidiano. Encontra-se também uma descaracterização do professor, que promove as interações necessárias com os estudantes, mediadas pelo processo de apropriação do conhecimento. Ou seja, a indispensável participação do professor não é entendida como transmissão de conhecimento, como ensino, sendo reduzida a uma espécie de acompanhamento da aprendizagem que ocorreria de forma autônoma desde o início do processo educativo. No limite, trata-se do postulado segundo o qual o aluno deve aprender sozinho, aprender a aprender.

Ou seja, quanto menos o professor ensinar, melhor a aprendizagem pelo aluno. São pedagogias que defendem a limitação do indivíduo às esferas da vida cotidiana. Esse processo pode ser considerado alienante, que, segundo Duarte (1996) e Heller (1991), se dá quando o indivíduo é impedido de se apropriar das esferas de objetivações genéricas não cotidianas, objetivações genéricas para-si. Estas pedagogias mostram-se sintonizadas com a ideologia da classe dominante. Dentre elas estão "o construtivismo, a pedagogia do professor reflexivo, a pedagogia das competências, a pedagogia dos projetos e a pedagogia multiculturalista." (DUARTE, 2010, p. 33).

Entende-se que, a partir de uma perspectiva histórico-cultural, a escola deve socializar o conhecimento. Porém, esta é uma lógica socialista e, por isso, nunca estará confortável numa sociedade capitalista (SAVIANI, 2008). O capitalismo 
defende uma educação para todos, porém, com a ressalva implícita e, algumas vezes explícita, de que a educação para a classe trabalhadora seja diferente.

Um exemplo desse pensamento, embora não seja o debate fulcral deste trabalho, mas faz-se necessário devido ao contexto desta discussão, é a política do Banco Mundial (BM) para a "socialização do conhecimento" para países como o Brasil. O BM defende a adequação do ensino superior ao mercado de trabalho, além de que seja adaptado às diferentes classes sociais. Propõe uma universidade de excelência, voltada à pesquisa, destinada aos cidadãos das classes superiores. Incentiva a existência de uma universidade para formar profissionais para o mercado de trabalho, cidadãos de classe média. $\mathrm{E}$, por último, propõe escolas profissionalizantes destinadas aos egressos do ensino médio e voltadas aos cidadãos das classes subalternas (LEHER, 2001).

Não é estranho o fato de o trabalhador desejar que seu filho aprenda na escola tudo o que ele não teve oportunidade de aprender. A estranheza, portanto, reside no fato de que os próprios intelectuais que foram formados pela escola (e que auferem seus estipêndios na escola) estabeleçam e ou defendam pedagogias que impedem a socialização do conhecimento para todas as classes sociais.

O adolescente é aquele que, num futuro próximo, escolherá uma profissão e começará a preparação para uma atividade profissional. Tanto a escola, quanto a família, ou melhor, a sociedade em geral, exigir-lhe-á tal postura. O problema reside na forma como a educação escolar vem tomando em relação a esta questão. Martins (2004) chama a atenção para o fato de que as políticas educacionais têm se centrado no treinamento de indivíduos a fim de satisfazer os interesses do mercado. Obviamente que o assunto sobre a inserção do indivíduo no mercado de trabalho deve estar na pauta da educação escolar, porém, conforme afirma a referida autora, a redução da educação à formação de competências é que deve ser objeto premente de análise crítica, "posto o empobrecimento que incide sobre os fins educacionais, convertidos em meios para uma, cada vez maior, adaptação passiva dos indivíduos às exigências do capital” (MARTINS, 2004, p.53).

A tarefa da educação escolar não consiste apenas em formar indivíduos para o mercado de trabalho. Isso seria muito pouco. Os conhecimentos científicos produzidos ao longo da história do desenvolvimento humano, quando transmitidos 
pelo professor e apropriados pelos alunos, contribuem, decisivamente, para o desenvolvimento geral do indivíduo, de sua personalidade.

\section{CONSIDERAÇÕES FINAIS}

Considerando-se que, para a psicologia histórico-cultural, a adolescência é um momento privilegiado tanto pelo desenvolvimento do pensamento por conceitos, como pela consequente formação da concepção de mundo e desenvolvimento da autoconsciência, a hipótese deste trabalho é a de que a educação escolar pode contribuir decisivamente, por meio do ensino do conhecimento sistematizado, para o desenvolvimento psíquico e para a formação da personalidade dos adolescentes no sentido da superação dos limites da vida cotidiana.

Diante da especificidade da educação escolar, qual seja: a socialização do conhecimento sistematizado (SAVIANI, 2008), este artigo defende que a prática pedagógica caracterizada pela transmissão de conteúdos clássicos, o saber sistematizado, pode proporcionar o desenvolvimento psíquico do aluno, conduzindoo ao processo de superação por incorporação das funções psicológicas espontâneas às funções psicológicas voluntárias, ao favorecer o salto qualitativo para o pensamento conceitual.

Nesse ponto, uma pergunta se nos apresenta: a escola tem executado seu papel na transmissão de conhecimentos clássicos, sistematizados, para que haja a formação dos verdadeiros conceitos científicos e não dos pseudoconceitos? Pois bem, a assimilação dos conceitos científicos começa com as explicações do professor. Luria (1990) afirma que o desenvolvimento do pensamento por conceitos depende das operações teóricas que a criança aprende na escola.

O autor explicita que, quando o professor sistematiza e programa a transmissão do conhecimento científico, tal processo resulta na formulação de conceitos científicos e não cotidianos. Pode-se fazer aquela pergunta de outra maneira, qual seja: seria possível dizer que as pedagogias hegemônicas têm produzido nos alunos os pensamentos por conceitos? Segundo Duarte $(2006 ; 2010)$, a resposta seria não, pois estas pedagogias reduzem o ensino ao cotidiano do aluno 
e descaracterizam o papel do professor como responsável pela transmissão do conhecimento clássico.

Se a adolescência é um período particularmente importante na formação da concepção de mundo, para a manifestação da autoconsciência, é importante que a educação escolar supere o limiar da cotidianidade, supere a lógica do capital, supere pressupostos superficiais, imediatistas e fragmentados. E, tratando-se de educação escolar, esta superação deve ocorrer a partir da educação infantil. Pois, ao que parece, o grande problema enfrentado no âmbito da educação escolar de adolescentes é que esse momento de viragem explicita objetivamente o produto oculto da formação antecedente.

\section{RICARDO ELEUTÉRIO DOS ANJOS}

Psicólogo, mestre e doutorando em Educação Escolar pela UNESP/Araraquara. Integrante do Grupo de Pesquisas cadastrado no CNPq com o título "Estudos Marxistas em Educação", ligado ao Departamento de Psicologia da Educação da UNESP. Professor de Psicologia Escolar e Educacional na UNOESTE.

\section{REFERÊNCIAS}

ARIĖS, P. História social da criança e da família. Rio de Janeiro: Zahar, 1978.

BOCK, A. M. B. A perspectiva sócio-histórica de Leontiev e a crítica à naturalização da formação do ser humano: a adolescência em questão. Cad. Cedes, Campinas, vol. 24, n. 62, p. 26-43, abril 2004.

DUARTE, N. Educação escolar, teoria do cotidiano e a escola de Vigotski. Campinas: Autores Associados, 1996. (coleção polêmicas do nosso tempo; v. 55).

DUARTE, N. A anatomia do homem é a chave da anatomia do macaco: A dialética em Vigotski e em Marx e a questão do saber objetivo na educação escolar. Educação \& Sociedade, ano XXI, nº 71, p. 79-115, Julho/2000.

DUARTE, N. As pedagogias do "aprender a aprender" e algumas ilusões da assim chamada sociedade do conhecimento. Revista Brasileira de Educação, n. 18. p. 35-40, Set/Out/Nov/Dez 2001.

DUARTE, N. O debate contemporâneo das teorias pedagógicas. In: MARTINS, L. M.; DUARTE, N. (Orgs.). Formação de professores: limites contemporâneos e alternativas necessárias. São Paulo: Cultura Acadêmica, 2010. 
ELKONIN, D. B. Desarrollo psíquico de los niños. In: SMIRNOV, A. A. et al. Psicología. México: Grijalbo, 1960. p. 493-559.

GRIFFA, M. C.; MORENO, J. E. Chaves para a psicologia do desenvolvimento: adolescência, vida adulta, velhice. Tomo 2. $6^{\text {a }}$ ed. São Paulo: Paulinas, 2010.

HELLER, A. Sociología de la vida cotidiana. Barcelona: Ediciones Península, 1991.

ISAMBERT-JAMATI, V. A adolescência na sociedade moderna. Análise Social, vol. IV, n. 14, 1966, p. 185-197. Disponível em: http://analisesocial.ics.ul.pt/documentos/1224167546B2sPA2qt0Dm30EC7.pdf. Acesso em 10 de Abril, 2012.

KNOBEL, M. A síndrome da adolescência normal. In: ABERASTURY, A.; KNOBEL, M. Adolescência Normal. $10^{\mathrm{a}}$ ed. Porto Alegre: Artes Médicas, 1992. p. 24-62.

LEHER, R. Projetos e modelos de autonomia e privatização das universidades públicas. In: GENTILI, P. (Org.) Universidades na penumbra: neoliberalismo e reestruturação universitária: Cotez, 2001.

LEONTIEV, A. N. Las necesidades y los motivos de la actividad. In: SMIRNOV, A. A. et al. Psicología. México: Grijalbo, 1960. p. 341-354.

LURIA, A. R. Desenvolvimento cognitivo: seus fundamentos culturais e sociais. São Paulo: Ícone, 1990.

MARTINS, L. M. Da formação humana em Marx à crítica da pedagogia das competências. In: DUARTE, N. (Org.). Crítica ao fetichismo da individualidade. Campinas: Autores Associados, 2004. p. 53-73.

MARX, K. O capital: crítica da economia política: livro I. São Paulo: Editora Nova Cultural, 1996. v. 1. (Os Economistas).

MASCAGNA, G. C. Adolescência: compreensão histórica a partir da escola de Vigotski. 2009. 184f. Dissertação (Mestrado) - Universidade Estadual de Maringá, Maringá, 2009.

OZELLA, S. A adolescência e os psicólogos: a concepção e a prática dos profissionais. In: OZELLA, S. (Org.). Adolescências construídas: a visão da psicologia sócio-histórica. São Paulo: Cortez, 2003. p. 17-40.

PALACIOS, J.; OLIVA, A. A adolescência e seu significado evolutivo. In: COLL, C.; MARCHESI, A.; PALACIOS, J. Desenvolvimento psicológico e educação. $2^{a}$ ed. Porto Alegre: Artimed, 2004, p. 309-322. v. 1.

SAVIANI, D. Pedagogia Histórico-Crítica: primeiras aproximações. $10^{\mathrm{a}}$ ed. Campinas: Autores Associados, 2008. 
VIGOTSKI, L. S. A construção do pensamento e da linguagem. $2^{a}$ ed. São Paulo: Martins Fontes, 2010.

VIGOTSKII, L. S. Aprendizagem e desenvolvimento intelectual na idade escolar. In: VIGOTSKII, L. S.; LURIA, A. R.; LEONTIEV, A. N. Linguagem, desenvolvimento e aprendizagem. $10^{a}$ ed. São Paulo: Ícone, 2006. p. 103-117.

VYGOTSKI, L. S. Obras escogidas. Tomo IV. Madri: Visor, 1996.

VYGOTSKY, L. S. Pensamiento y lenguaje: teoría del desarrollo cultural de las funciones psíquicas. Ediciones Fausto, 1995. Disponível em: http://psikolibro.blogspot.com. Acesso em 18 de Junho de 2011. 